\title{
ПЕРСПЕКТИВЫ РАЗВИТИЯ НЕСЫРЬЕВОГО НЕЭНЕРГЕТИЧЕСКОГО ЭКСПОРТА РОССИИ В КИТАЙ
}

\section{THE PROSPECTS OF THE RUSSIAN NON-RAW-MATERIALS, NON-ENERGY EXPORTS DEVELOPMENT TO CHINA}

M. Eliseeva

Summary. The development of Russia-Sino trade cooperation is one of the priority directions of Russian foreign policy. The article analyzes the Russian non-raw-materials and non-energy exports to China. The current state and its development potential were assessed. The conclusion was that this direction harboured enormous potential. If to take into account the changes in the Chinese economic, this potential can be revealed.

Keywords: non-raw-materials and non-energy exports, NNE, Russian export, trade cooperation, dual circulation strategy.
B последнее десятилетие направления развития Китая и процессы трансформации, происходящие в нем, наращивают свое влияние на глобальную экономику, что привлекает все большее внимание со стороны мирового сообщества, в том числе России. Согласно утвержденной в 2016 г. Концепции внешней политики РФ [1], сотрудничество с ключевой экономикой региона Восточной Азии, Китаем, является одним из региональных приоритетов внешней политики России.

Важным элементом российско-китайского внешнеполитического взаимодействия является торговля, объем которой в 2020 г. достиг 103,97 млрд. долл. США, удельный вес - 18,31\% от совокупного показателя Внешней торговли РФ [2]. Что является наибольшей величиной в страновом разрезе, несмотря на снижение на 6,72\% по сравнению с предшествующим годом. Однако, данный показатель сложен по кодам ТН ВЭД ЕАЭС и не включает форму № 8-ВЭС-рыба. Поэтому в основу исследования была взята методология расчета национального проекта РФ «Международная кооперация и экспорт» («МКиЭ»), исходя из которой объем внешней торговли России с Китаем составляет 104,06 млрд. долл. США, при фактическом стоимостном показателе экспорта из России в размере 49,15 млрд. долл. США против 46,06 млрд. долл. США, заявленных ФТС России [3]. Вместе с тем объем российских поставок несырьевых неэнергетических товаров в Китай не превышает 35\%.

\author{
Елисеева Мария Владимировна \\ Аспирант, Финансовый университет при \\ Правительстве Российской Федерации (г. Москва) \\ mveliseeva2020@edu.fa.ru
}

Аннотация. Развитие торгового сотрудничества России с китайским партнером является одним из приоритетных направлений внешней политики страны. В статье проведен анализ несырьевого неэнергетического экспорта России в Китай. Была дана оценка текущего состояния и потенциала его развития. Сделан вывод, что данное направление таит в себе колоссальный потенциал, который может быть раскрыт при учете процессов трансформации, происходящих в китайской экономике.

Ключевые слова: несырьевой неэнергетический экспорт, ННЭ, российский экспорт, торговое сотрудничество, стратегия «двойной циркуляции».

В этой связи реализация российского проекта «МКиЭ», целью которого является увеличение несырьевого неэнергетического экспорта (ННЭ) к 2030 г. не менее чем на 70\% по сравнению с 2020 г. [4], в сопряжении с национальной стратегией Китая «двойная циркуляция» может позволить России не только углубить отношения с зарубежным партнером, но и изменить устоявшуюся ориентацию на сырьевую структуру национального экспорта. Что становится возможным в случае синергии накопленного опыта, переориентации экономики Китая с экспорта на внутреннее потребление и преимуществ новых (электронных) каналов сбыта.

Текущее состояние ННЭ России в Китай характеризуется положительной динамикой, прежде всего за счет наращивания поставок товаров категории нижнего передела. За период 2016-2020 гг. российский ННЭ на территорию Китая увеличился на 97,34\% с 8,26 млрд. долл. США до 16,30 млрд. долл. США, сохранив положительную динамику в год простоя производства на фоне пандемии COVID-19 (рис. 1).

В 2020 г. основным поставщикам продукции ННЭ на региональном уровне стали Центральный, Сибирский и Дальневосточный федеральные округа, которых удельный вес составил более $60 \%$ совокупного объема поставок исследуемой группы товаров. В разрезе по субъектам федерации - г. Москва, Свердловская 


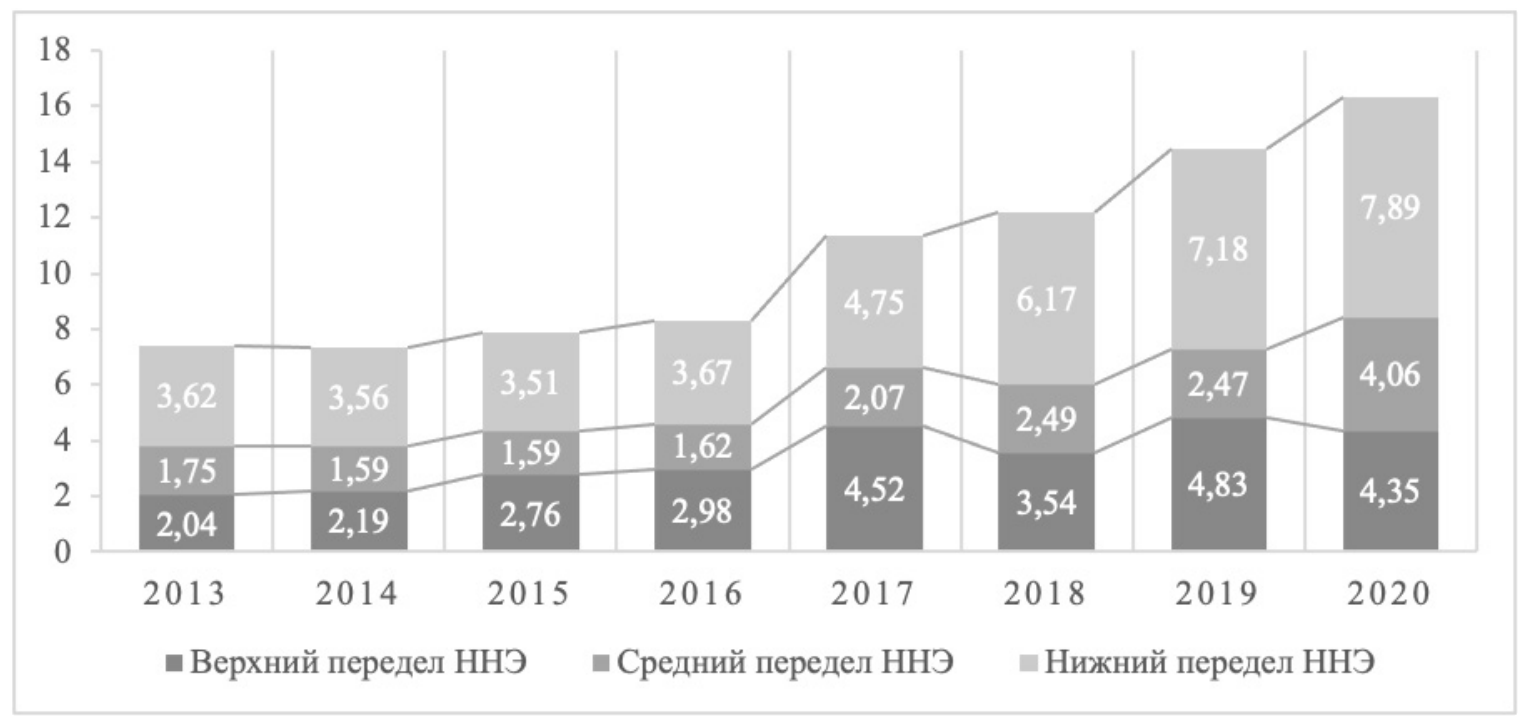

Рис. 1. Динамика несырьевого неэнергетического экспорта России в Китай по переделам в период 2013-2020 гг., млрд. долл. США

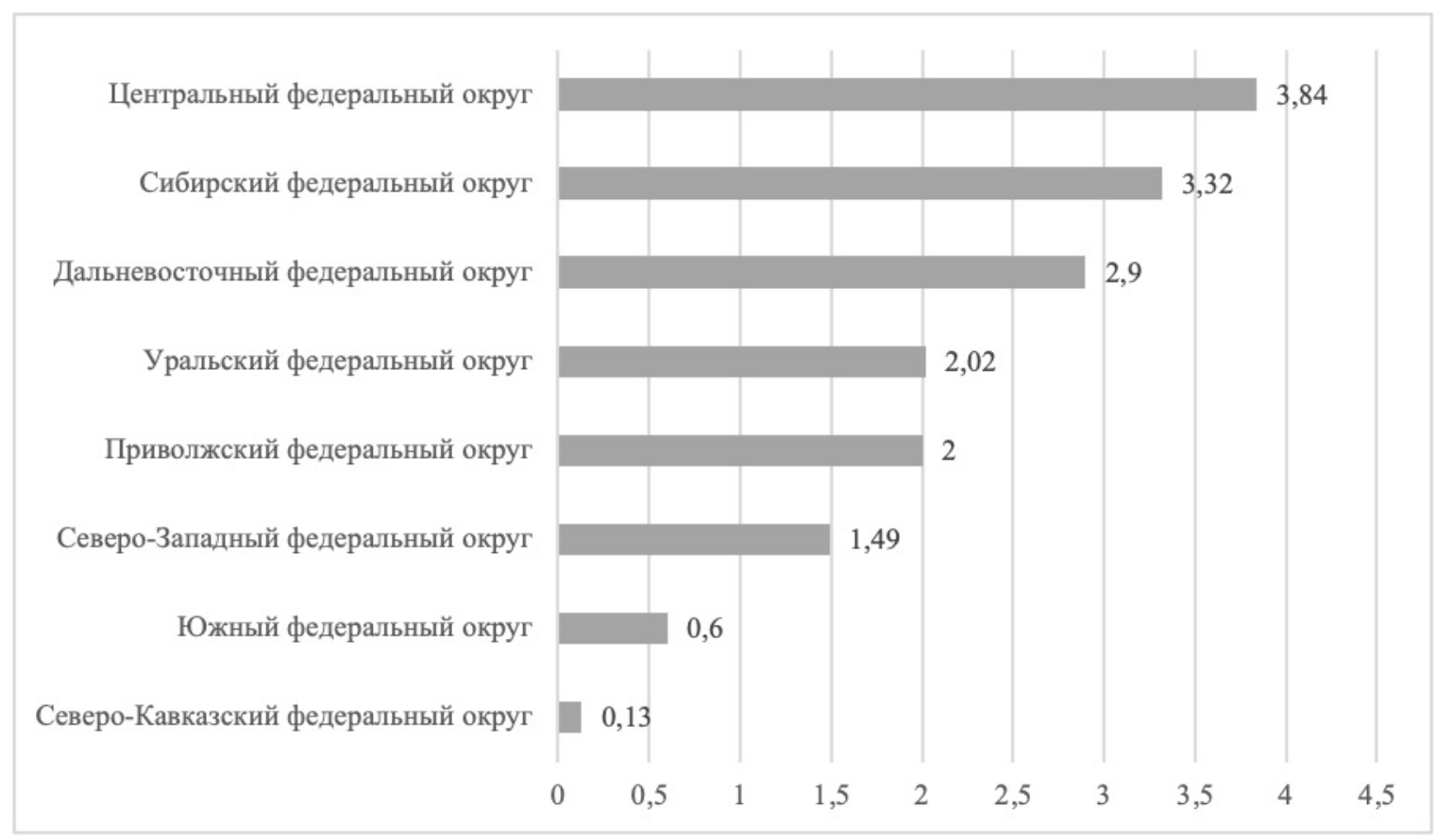

Рис. 2. Рейтинг регионов-поставщиков ННЭ России в Китай в 2020 г., млрд. долл. США

и Иркутская области, Приморский и Красноярский края (рис. 2).

Настоящая картина сложилась под влиянием ряда факторов, к которым относятся следующие:

1. Географическая близость и развитость транспортной инфраструктуры. Конечная стоимость товаров и их конкурентоспособность зависит от транспортных издержек, в особенности для продукции агро- и лесопромышленного комплексов. По этой причине такие регионы, как Дальневосточный и Сибирский федеральные округа являются наиболее перспективными поставщиками ННЭ на территорию Китая.

2. Высокая концентрация головных офисов российских компаний и представительств международ- 
Таблица 1. Товарная структура ННЭ России в Китай в 2020 г., млрд. долл. США

\begin{tabular}{|l|l|l|l|}
\hline № $\mathbf{n} \mathbf{n}$ & Товарная группа & Млрд долл. США & Удельный вес, \\
\hline & Итого, в том числе: & $\mathbf{1 6 , 3 0}$ & $\mathbf{1 0 0 , 0 0}$ \\
\hline 1 & Продовольствие и сельскохозяйственное сырье, кроме текстильного & 3,94 & 24,17 \\
\hline 2 & Целлюлозно-бумажные изделия & 3,59 & 22,02 \\
\hline 4 & Продукция металлургии & 2,95 & 18,10 \\
\hline 5 & Машины, оборудование и транспортные средства & 2,23 & 13,68 \\
\hline 6 & Продукция химической промышленности, каучук & 1,65 & 10,12 \\
\hline 7 & Топливно-энергетические товары & 0,49 \\
\hline 8 & Драгоценные камни и металлы, изделия из них & 0,08 & 0,37 \\
\hline 9 & Текстиль, текстильные изделия и обувь & 0,06 & 0,12 \\
\hline & Другие товары & 0,02 & 10,92 \\
\hline
\end{tabular}

ных организаций в административных центрах регионов, из которых осуществляется экспортная деятельность.

3. Наличие высокого уровня производственной активности АПК и развитого многоотраслевого промышленного комплекса, что относится прежде всего к Красноярскому краю и Свердловской области.

В свою очередь структура ННЭ преимущественно представлена тремя товарными группами, на которые приходится более 64\% совокупного объема поставок несырьевых неэнергетических товаров (табл. 1):

1. Продовольствие и сельскохозяйственное сырье - 3,94 млрд. долл. США, среди которых наибольшим спросом пользуются рыба и морепродукты, мясо и субпродукты;

2. Целлюлозно-бумажные изделия - 3,59 млрд. долл. США. Помимо этого, пиломатериалы (код ТН ВЭД ЕАЭС 4407) занимают 1-е место в рейтинге экспортируемых несырьевых товаров в Китай, чей стоимостной объем сложится в сумме 2,25 млрд. долл. США. Для сравнения, показатель экспорта ключевого несырьевого энергетического товара, нефтепродуктов, составил 2,19 млрд. долл. США;

3. Продукция металлургии, экспорт которой достиг 2,95 млрд. долл. США за счет увеличения потребления меди на 51,82\% по сравнению с 2019 г. Что произошло под влиянием двух факторов. Во-первых, подъема в промышленности, который обусловлен новыми мероприятиями правительства по стимулированию экономического роста. Во-вторых, в силу сокращения добычи сырья на территории Китая из-за ограничений, вызванных пандемией COVID-19, и ужесточения экологических стандартов.
Помимо товаров, входящих в вышеуказанные группы, к основной продукции, поставляемой в Китай, относятся механическое оборудование и техника, компьютеры $(1,84$ млрд. долл. США), секретный экспорт (1,61 млрд. долл. США) и удобрения (0,84 млрд. долл. США). Удельный вес последней в структуре экспорта постепенно сокращается за счет диверсификации структуры ННЭ, так в период 2013-2020 гг. наблюдается снижение с 13\% до 3,24\%.

Согласно опубликованному в 2021 г. Рейтингу перспективности стран для экспорта, Китай - это одно из наиболее перспективных направлений ННЭ из России [5]. В географии потенциальных возможностей развития исследуемого сегмента внешней торговли страна занимает 3-е место после Узбекистана и Казахстана. Эксперты отмечают, что в рамках российско-китайского торгового сотрудничества наибольшими перспективами развития ННЭ обладают такие отрасли, как металлургия, агропромышленный и лесопромышленный комплексы. Что нашло свое отражение в рассмотренной выше статистике.

Таким образом, проанализировав динамику развития несырьевого неэнергетического экспорта России в Китай и работы экспертов по вопросам трансформации китайской экономической модели и возможностям модернизации российской экономики $[6,7,8]$, можно сделать следующие выводы относительно перспектив развития исследуемого направления.

Во-первых, Китай становится крупнейшим рынком сбыта потребительских товаров в мире, на котором благодаря активному развитию электронной коммерции и реализации национальной стратегии «двойная циркуляция» происходит стремительное расширение внутреннего спроса, в том числе в сельских районах. Данный процесс сопровождается трансформацией общей концепции потребления: с количества на качество [9]. 
Во-вторых, в силу сложной экологической ситуации в Китае, связанных с высоким уровнем загрязнения воздуха, рек и пахотных земель, страна столкнулась с продовольственной проблемой и вынуждена удовлетворять внутренний спрос путем импорта продукции АПК из-за рубежа. Согласно оценкам экспертов, на сегодняшний день рынок продовольствия - это наиболее растущий сегмент потребительского рынка Китая.

В-третьих, китайский экологический разворот, происходящий в последние годы, стал весомым фактором влияния на развитие промышленного производства страны, которое является важнейшим сектором национальной экономики. Ограничения и критерии, предлагаемые Министерством экологии и окружающей среды КНР, приводят не только к разнонаправленному движению цен на металлы и сырье для их производства на глобальном рынке, но и к увеличению импорта алюминия, меди, цинка и других металлов.

В-четвертых, в эпоху развития цифровизации и трансграничной электронной коммерции происходит снижение и постепенное сокращение барьеров в сфе- ре торговли. Благодаря упрощению процесса совершения сделок в рамках интернет-платформ В2В и В2С, преимущественно принадлежащим Alibaba Group, производители и торговые компании из Китая расширили охват российских потребителей и активно используют открывшиеся возможности. Россия как заинтересованная сторона в развитии не только сотрудничества с Китаем, но и собственного несырьевого потенциала должна на правительственном уровне способствовать выходу национальных поставщиков на наиболее перспективные зарубежные рынки.

Подводя итог исследования, можно сказать, что несырьевой неэнергетический экспорт России таит в себе колоссальный стратегический и экономический потенциал. Ключевыми конкурентами страны являются Бразилия и Великобритания, которые не обладают географическим преимуществом и исторически сложившейся глубиной сотрудничества с китайским партнером. В этой связи со стороны России требуется осуществление мероприятий по развитию транспортной инфраструктуры и углубление диверсификации ННЭ с учетом процессов трансформации потребления в Китае.

\section{ЛИТЕРАТУРА}

1. Указ Президента Российской Федерации от 30 ноября 2016 года $N 640$ «0б утверждении Концепции внешней политики Российской Федерации».

2. Итоги внешней торговли с основными странами [Электронный ресурс] // Федеральная таможенная служба: [caйт]. URL: https://customs.gov.ru/statistic (дата обращения: 11.10.2021).

3. Экспорт регионов [Электронный ресурс] // Аналитический портал: [сайт]. URL: http://regionstat.exportcenter.ru/hs/list/ (дата 06ращения: 03.09.2021).

4. Указ Президента Российской Федерации от 21 июля 2020 года N474 «0 национальных целях развития Российской Федерации на период до 2030 года».

5. Рейтинг перспективности стран для экспорта, 2021 [Электронный ресурс] // A0 «Российский экспортный центр»: [caйт]. URL: https://www.exportcenter. ru/upload/rating_country/Рейтинг_2021.pdf (дата обращения: 11.10.2021).

6. Liu Wei, Chen Yanbin. China's Economic Growth and High- Quality Development: 2020-2035 // China Economist, 2021.— № 1.—C. 2-17.

7. Yang Danhui. Pathways for Elevating China's Opening-up under the New Development Paradigm // China Economist, 2021.— № 3.— C. 84-112.

8. Перспективы наращивания российского несырьевого экспорта / А.Н. Спартак [и др.] [Электронный ресурс] // Фонд «Центр стратегических разработок»: [сайт]. URL: https://www.csr.ru/upload/iblock/69a/69a4bb385096875672f351c264f09f97.pdf (дата обращения: 07.09.2021).

9. China consumer report, 202 / Antonio Achille [и др.] [Электронный ресурс] // McKinsey \& Company: [caйт]. URL: https://www.mckinsey.com/ /media/ mckinsey/featured\%20insights/china/china\%20still\%20the\%20worlds\%20growth\%20engine\%20after\%20covid\%2019/mckinsey\%20china\%20 consumer\%20report\%202021.pdf (дата обращения: 03.09.2021). 